\title{
Factors Influencing Decisions on Delay Claims in Construction Contracts for Indian Scenario
}

Nitin Chaphalkar, (College of Engineering Pune, India)

K. C. Iyer, (Indian Institute of Technology, Delhi, India)

\begin{abstract}
Construction industry in India is second largest industry in the economy, next to agriculture. Currently, infrastructure development construction projects occupy a key position. In any construction project contract time and cost overruns are common, which gives rise to claims leading to disputes. These disputes if not handled properly tend to consume time and money of all parties to the contract. To resolve the dispute in optimum time, it is essential to understand the root cause of disputes as early as possible. Hence there is a need of analyzing the disputes scientifically. The present study reveals from the study of arbitration awards that the causes for delay claims can be grouped in domains and the probable decisions to the disputes can be traced through the probing questions considered by decision makers. This paper attempts to identify questions related to disputes for Indian scenario through literature, arbitration awards, court cases and discussions with professionals.
\end{abstract}

Keywords: Contract management; Delay claims; Claim management; Arbitration; Dispute resolution

\section{Introduction}

Due to the very nature of the construction industry and varying contract conditions across different projects, contract claims are inevitable. Though claims are raised in numerous areas, delay claims are found to be most common. Yates and Epstein (2006) have observed that delays on construction projects and the claims originating from such delays are an integral part of the modern construction process. According to them, the construction delay claim process commences at the project inception itself. Referring to numerous past studies, Scott et al (2004) conclude that construction projects have a tendency to suffer from delays and such delays carry potential losses for all parties: for the employer (client, owner) through loss of use, and for the contractor and subcontractors through their prolonged presence on site. However, a delay in a construction project can be caused either by owner or by the contractor or by numerous other reasons.

After studying 130 projects Al-Momani (2000) found that poor design, and negligence of the owner, change orders, weather conditions, site conditions, late delivery, economic conditions and increases in quantities are the main causes of delay. Odeh and Battaineh (2002) have identified 28 causes of delay categorized in eight major groups through questionnaire survey in Jordan. Aibinu and Jagboro (2002) have identified six effects of delays as time overrun, cost overrun, dispute, arbitration, total abandonment, and litigation for Nigerian construction industry. Kumarswamy and Yogeswaran (2003) opine that the detailed claims related to extension of time are often submitted towards the end of the construction period which is one of the contributory factors to the late assessment of claims. Scott (1997) has studied the attitudes of contractors and supervisors towards delay claims. In the Indian context, lyer and Kalidindi (2002) have identified the 'Time Delay and Extension clause' as second most critical clause next to Final and Binding Power in construction contracts. It is observed that there is much concern about disputes related to delay in construction projects. Satyanaraya and lyer (1996) have identified 23 reasons causing delay to projects. Taking lead from the 
works discussed above, the current paper focuses on the identification of various factors causing delay in construction projects.

As a first step in the study it is thought essential to understand various aspects of disputes arising out of time delay and extension clauses and identify the cases and relevant data that would provide greater insight into the disputes. Cases related to construction disputes are found available in the two leading reporters of India: Arbitration Law Reporter (Arb LR) and All India Reporter (AIR). It is also found that these reporters publish only those cases whose judgements are pronounced in the High courts or the Supreme Court of India. As such these courts being primarily appellate courts in India, they generally look if there has been any "error of law" in the judgement of the case for which the appeal has been filed. Hence, the actual facts or evidences of the cases remain unknown to the reader of the cases. Therefore, to gather detailed information of the missing part of the background or the facts of the cases arbitration awards were taken for study.

\section{Findings from the Awards related to Delay Claims}

A total of 52 arbitration awards were collected through personal contacts with arbitrators or government officials. As the arbitration awards are not publicized and are required to be kept confidential, the names of the parties to contract are not revealed in the discussion below. Incidentally, in all the awards the claimants were private parties, while the respondents included both private and public bodies, with majority of them being government departments or public sector undertakings. Contract forms used were mostly Central Public Works Department (CPWD), Military Engineer Services (MES), Railways or State Public Works Departments and were related to different construction sectors.

It was found during the study that out of 52 arbitration awards available for study, 38 awards pertained to delay related claims. The delays were observed due to numerous reasons like late handing over of site, late issue of drawings, late supply of materials, delayed payments, delay on the part of sub contractor, etc. In many awards, more than one reason was found to be responsible for delay, e.g., in one case, there was delay in supply of material as well as delay in payment of bills by the owner, while in another case, there were orders of extra items through change order, but delay in finalizing their rates leading to non-payment of bills on time, etc. For the purpose of analysis, the claims were grouped in broad areas according to the reason causing delay and accordingly the awards were classified on the basis of broad reasons under which the claims had arisen. The distribution of awards under various reasons (behind the claims) is shown in the Table.

Subsequently, various types of claims raised by the contractor due to above reasons were also studied in detail to understand the logic behind allowing or disallowing a particular delay claim by the arbitrator. Different types of claims raised by contractor under 'Time Delay and Extension' in the awards have been observed as follows.

- Reimbursement of variation and escalation due to extended stay

- Granting extension of time for delays

- De/Remobilization charges for carrying out delayed work

- Compensation for idling resources due to delays

- Compensation for loss of overheads and profits

- Compensation for extra expenditure incurred on overheads, establishment and other supervisory expenditure due to extended stay

- Release of amount withheld towards liquidated damages

- Compensation for mental agony, torture, stress and defaming

Chaphalkar, N and Iyer K C (2014) 'Factors influencing decisions on delay claims in construction contracts for Indian scenario', Australasian Journal of Construction Economics and Building, 14 (1) 32-44 


\begin{tabular}{|c|l|c|}
\hline Sr. No. & \multicolumn{1}{|c|}{ Reason causing delay } & No. of awards \\
\hline $\mathbf{1}$ & Delay due to late handing over of site & $\mathbf{1 5}$ \\
\hline $\mathbf{2}$ & $\begin{array}{l}\text { Delay due to late issue of drawings } \\
\text { Delay due to late supply of material, equipment and services like } \\
\text { water \& electricity called as late supply of resources }\end{array}$ & $\mathbf{0 8}$ \\
\hline $\mathbf{3}$ & $\begin{array}{l}\text { Delay due to change order } \\
\text { Delay due to non receipt of RA bills/mobilization advance/ } \\
\text { escalation on time }\end{array}$ & $\mathbf{0 6}$ \\
\hline $\mathbf{5}$ & Delay due to subcontractor/ vendor/another agency & $\mathbf{0 6}$ \\
\hline & Total & $\mathbf{4 6}$ \\
\hline
\end{tabular}

Table Distribution of reasons causing delays

It was observed that in 35\% cases, there was no award granted and the main reason for not granting the award was the contractor's failure to give notice on time to owner or to produce the evidence of his loss. Notices were given utmost importance by the arbitrators and in some cases, where no notices were served by contractor, the claims were rejected. However, yet in another case, the notice requirement was not complied and the compensation was paid as a reasonable remuneration for work done on the basis of quantum meruit. To assess the loss claims by the contractor, evidences presented in the form of bills, records were considered. Although in certain instants the delay appeared to be fully attributable to the owner, yet no claim was allowed. However, if the extended stay was beyond the control of both the parties, $50 \%$ compensation was sanctioned.

In another award, the work was executed under extra item at the request of the owner, but the prices were not decided. The arbitrator allowed the payment of reasonable remuneration, as the object of paying for damages is to put the injured party in a position, as if the promise has been performed.

There were also claims on account of mental torture and loss of opportunity by a few contractors. Considering them to be remote and not falling under the purview of Clause 73 of Indian Contract Act, these claims were not allowed in any of the cases. As per Section 73 of the Indian Contract Act, the primary duty of the party who complains of the breach of contract by the defendant is to prove that he has suffered loss as a consequence of the breach, as well as its extent. If he is unable to prove the loss suffered by him, he cannot recover anything. In a few cases it was also observed that the owner has not levied liquidated damage, instead allowed extension of time. In these cases the arbitrators concluded that the delay is attributable to owner, and hence the contractor was entitled for compensation.

After the initial study of arbitration awards and extracting reasons for delays as given in Table, the first six reasons which contribute to about $85 \%$ of the total reasons were used for further study. These reasons are called 'domains' in all subsequent discussion. These domains are listed below and the detailed findings from awards under each domain are discussed in the following sections.

- Delay due to 'Late handing over of site'

- Delay due to 'Late issue of drawings'

- Delay due to 'Late supply of material, equipment and services like water \& electricity called as late supply of resources'

- Delay due to 'Change order'

- Delay due to 'Release of payment of RA bills/ mobilization advance/ escalation'

- Delay due to 'Subcontractor/ vendor/another agency'

Chaphalkar, N and Iyer K C (2014) 'Factors influencing decisions on delay claims in construction contracts for Indian scenario', Australasian Journal of Construction Economics and Building, 14 (1) 32-44 
During the case study cases it is found that although the contractors have been trying to put onus of delay entirely on the owners and seek compensation, the contractors do not get their claims all the time. The case study has revealed certain logics followed by the arbitrators while deciding to allow or disallow certain claims. These logics are in the form of probing questions that helped arbitrators in their decisions. Hence, as the next step, the logics or the probing questions that are considered by the arbitrator while giving decisions are traced. These questions are named as 'factors'. Identification of the factors influencing decisions is considered essential as they contribute in building up the thought process of the arbitrator.

\section{Identification of Factors Influencing to Decision}

In this section various factors that are identified under different domains are presented. Identification of these factors is supported by relevant arbitration or court cases for better comprehension.

\section{Identification of Factors under Delay due to "Late Handing Over of Site"}

During the study it was found that the claims due to late handing of site was noticed in 15 cases and only in five cases the arbitrator had awarded in favour of the contractor. In one case, though there was delay in handing over of site, yet the work was completed in 17 months as against the completion time of 30 months. The contractor had sought compensation for the delay in handing over of the site presumably for mobilizing additional resources for completing the work on time. This claim was denied by the owner and the arbitrator also rejected the claim stating that as the contractor did not submit either the revised schedule for early completion or the proof of overburden on account of revised schedule for early completion, the contractor was not entitled for any compensation. In yet another case related to delay in 'part' handing over of site, it was established by the arbitrator that although there was delay in handing over of part of the site, it did not hinder the progress of work as the contractor's resources were fully utilized in the progress of work in other parts of the site and as such there was no idling of contractor's resources requiring compensation. Thus in the case of delay in handing over of the part site, it is first ascertained whether the part handing over actually hampered the progress of work and if handing over of part site in claim was an activity on the critical path. However, if it is proven that it is a critical activity, then the delay is attributed to the owner and appropriate compensation is granted. On the other hand, if it is not a critical activity, then any claim by the contractor ceases to exist. Incidentally, in the instant case the contractor abandoned the work when the scope of work was increased and rates for the extra work were not agreed to between the parties and the owner had to invoke the foreclosure clause. Similarly in a number of other cases the claim was denied by the arbitrator as the proper evidences to support the claim like bills, or other relevant documents were not submitted by the contractor. Thus the above cases have prompted the following questions.

- Whether delay affected the project schedule?

- Whether the claim of the contractor is supported by documentary evidence?

When a dispute arises at the initial stage of the project due to non-handing over of entire site by a given date, it is mandatory for the contractor to give a written notice in time. Timely notice and its vetting by the owner representative make the contractor eligible for the claim. If the contractor fails to give notice in time, he has to at least prove that he had mobilized his resources that actually idled. Failing this he is not entitled for any claim. On the contrary, if owner proves that he had handed over the site on time and the contractor, being of poor means failed to start the work, entitle the owner to claim liquidated damages from contractor. In the case $A_{34}$, even though the site was handed over late by the owner, contractor never gave notice about it. On the contrary, the contractor gave a letter stating that he did not suffer any loss, and the liquidated damage was imposed by the owner, which was nonarbitrable in the eyes of law (lyer and Kalidindi 2002). In fact in cases of other domains too,

Chaphalkar, N and Iyer K C (2014) 'Factors influencing decisions on delay claims in construction contracts for Indian scenario', Australasian Journal of Construction Economics and Building, 14 (1) 32-44 
the matter of mutual exchange of notices between parties was closely examined by the arbitrators before arriving at the conclusion. Thus a question is identified - whether the notice was given by the contractor?

As discussed in the preceding paragraph the imposition of liquidated damage is the prerogative of the particular owner representative and the power to impose this does not lie with any one else other than the designated person in the contract. It is also concluded in several court judgments that this is a non-arbitrable issue in the eyes of law; and any imposition of the damage practically establishes the fact that the contractor is solely responsible for the delay putting a complete halt on any further decisions on the compensation for the delay. Hence non-imposition of this damage by the owner representative certainly gives a scope to the contractor for seeking compensation for the losses on account of delay. In three cases where owner did not levy liquidate damages and expressed themselves being gracious, arbitrator concluded that delay was attributable to the owner and accordingly, the claims were allowed in favour of the contractor, the claimant. Thus the owner's defense of being gracious by non-levying did not help to owner but proved otherwise and the awards were made in favor of contractor. This has prompted to identify the question - did owner invoke liquidated damage clause with or without its actual imposition?

In another case pertaining to the claims in a road project, some part of the road was crossing the railway line and as the owner did not coordinate with the railway authorities, this part of the road work could not be taken up on time. After waiting for some time for the clearance to commence the work on this part, the contractor demobilized his resources from the site. Subsequently when all clearances were obtained and contractor was asked to commence the work in this part, the contractor had to remobilize the resources. Demobilization and remobilization of resources had put the contractor in extra financial burden for which the contractor submitted his claim. In another case of a bridge project, the contractor had to remobilize the resources as the owner failed to clear encroachments by other contractor in time. While in the first case the owner had to depend on clearance from some other agency, while in the other case it was well within the powers of the owner to evict the past contractor to hand over the site to the new contractor. However, in both cases the contractor had to demobilize and remobilize his resources which entitled him for compensation. Detailed study of reasons put forth by the arbitrators in these cases prompted the following four questions.

- Was there any obstruction from a third party in handing over of site?

- Did owner have control over the third party?

- Did the contractor mobilize the resources in time to show his "readiness"?

- Whether delay in handing over of site resulted in additional resource mobilization and expenses to meet the scheduled date?

After finding the factual position, the legitimacy of the claim was to be established with respect to the legal standpoint of the case. In one of the case, the contract agreement categorically stipulated that the contractor would not get any compensation if starting of work is delayed on account of acquisition of land. Similar provision is also found to exist in contract forms state PWD (Clause-40) and Railways (Clause-17(3)) where contractor is denied any claim on account of delay in handing over of site. This situation has generated the question - whether conditions of contract expressly mention that no compensation due to delay in handing over of site is payable to the contractor?

In yet another award, submission of insurance policy and special method statement was prerequisite for starting the work and the contractor did not comply with the pre-requisites. Incidentally, the owner also did not have the possession of the site that he could hand it over to the contractor. While the contractor claimed for compensation on account of non-handing over of site on time, the owner took the position of the non-submission of required pre-

Chaphalkar, N and Iyer K C (2014) 'Factors influencing decisions on delay claims in construction contracts for Indian scenario', Australasian Journal of Construction Economics and Building, 14 (1) 32-44 
requite document by the contractor for handing over of site and denied the claim. The arbitrator while allowing the claim of the contractor advised that the two aspects in the claim: 'starting of work' and 'handing over of the site' be de-linked. In the given case the submission of the required documents was the pre-requisite for starting the work and not for handing over of the site and held owner responsible for the default. This establishes yet another probing question - whether there was any pre-requisite like submission of bank guarantee for security deposit, obtaining insurance, submission of methods statement, etc. before handing over of site? However the answer to this question should not be indirect, i.e., the way owner drew while denying the claim, but it should have a direct answer from the conditions of contract.

Thus in this domain a total of ten factors are identified as given below which are taken for the subsequent study.

Q.1 Did late handing over of site affect the project schedule?

Q.2 Did the contractor issue notice to the owner about the delay and its implications within "reasonable time"?

Q.3 Did the contractor mobilize the resources in time to show his "readiness"?

Q.4 Did the delay in handing over of site resulted in additional resource mobilization and expenses to meet the scheduled date?

Q.5 Was there any obstruction from third party in handing over of site?

Q.6 Did owner have control over the third party?

Q.7 Did conditions of contract expressly mention that no compensation due to delay in handing over of site is payable to the contractor?

Q.8 Was there any pre-requisite like submission of bank guarantee for security deposit, obtaining insurance, submission of methods statement, etc. before handing over of site?

Q.9 Did owner invoke liquidated damage clause with or without its actual imposition?

Q.10 Was the claim by the contractor on this issue supported by documentary evidence?

\section{Identification of Factors under Delay due to 'Late Issue of Drawings'}

During the study it was found that there were total of five cases available wherein the claims related to late issue of drawings were dealt with. The drawings form an important part of the contract documents. Drawings may be issued by the owner either at the tender stage itself or in stages during execution of work or the contractor may have to develop the drawings and get them approved by owner's representative before execution. Thus there are three types of conditions of contract that define these responsibilities. Generally there is no claim when drawings are issued along with tender document unless there is some change order necessitating issue of fresh drawings. However, in the second type where drawings are issued in stages by owner during execution and if there is delay in issue, the notice by the contractor is required to support his claim. On failure to notify about the delay in receipt of drawings and its consequences to the owner, the contractor forfeits his rights of getting compensation. In the third type where the drawings are to be developed by the contractor there arise three situations: delay from the contractor's side in preparation; delay from the owner's side in checking and approving; and delay from both the parties. For the first two situations, the responsibility of delay is easily fixed while in the third situation which constitutes a case of concurrent delay, the claim has to be resolved using apportionment. Hence in case of issue of drawings, it is essential to establish who is responsible for the issue of drawings. 
In a typical case of a power plant project, the contractor was supposed to prepare the drawings which were to be checked by the agency appointed by the owner. The concerned agency delayed the checking of drawings resulting delay in execution of project. In this case the owner (who was State PWD) was held responsible for the delay by the arbitrators and the contractor was awarded the compensation leading to the question - whether there was delay in approval of the drawings from owner?

In another case, there was delay in finalization of drawings but the owner did not levy liquidate damages and allowed extension of time. From the award it was not clear as to whose responsibility it was to issue the drawings, nor had the researcher access to the background documents of the award. However, since the arbitrator had allowed the claim of the contractor it can be concluded that the owner was responsible for delay in issuing drawings. As discussed in the previous section non-levying the liquidated damage by the owner gives a scope for the contractor to qualify for the claim, in this domain also similar situation is seen. Thus this leads to the question - did the owner invoke liquidated damage clause with or without its actual imposition?

In yet another case, it was proved that there was four months delay in execution of the project which was attributable to the owner on account of non-issue of layout drawing, the contractor claimed for idling of resources but failed to produce the evidence for payment. Hence the claim for compensation was rejected. This case prompted the question - whether the claim of the contractor is supported by the documentary evidence?

In any construction activity changes during execution is a common feature. These changes require revised drawings which delays the execution of the project. This issue is addressed by including the question - whether necessity of new drawings arose due to change in design or any other reason during execution of work?

Idling of resources mobilized by the contractor is a key issue if the issue of drawings is delayed. This issue is addressed by the question - did contractor's resources idle? Lastly, as discussed for the late handing over of site in the previous section, it is also thought appropriate to check whether the delay in issue of drawings actually affected the project schedule and whether the mutual exchanges of notices has taken place, as these are the common questions on which an arbitrator takes decision.

From the preceding paragraphs a total of eight factors are identified in this domain as given below and they are taken for the subsequent study.

Q.1 Did the delay in issue of drawings affect the schedule of work?

Q.2 Who was responsible for providing the drawings? (Note - In case a consultant issuing drawings is appointed by the owner, then the owner is held responsible, conversely if he/she is appointed by contractor, then the contractor is responsible).

Q.3 Was notice regarding the delay in issue of drawings served by owner/ contractor?

Q.4 Was the necessity of new drawings due to change in design or any other reason during execution of work?

Q.5 Did contractor's resources idle?

Q.6 Was there delay in approval of the drawings from owner?

Q.7 Did owner invoke liquidated damage clause with or without its actual imposition?

Q.8 Was the claim by the contractor on this issue supported by documentary evidence? 
Identification of Factors under Delay due to 'Late Supply of Material, Equipment and Utilities like Water \& Electricity called as Late Supply of Resources"

There was a total of eight cases available in this domain. In one of the cases, there was a delay in supply of structural steel which was not supplied at regular intervals by the owner. It was observed by the arbitrator that even though there was a random supply of material, it has not affected the overall schedule and the claim for compensation was not allowed. This case prompted the question - whether delay affected project schedule?

Like in previous section, it is also essential to establish as to who is responsible for supplying the resources. Responsibilities for the procurement of resources are well defined in the contract and delay due to non-availability of resources is attributable to the party responsible for such procurement. As far as owner supplied material is concerned, the contractor is compensated for delay in the supply of material by the arbitrator, of course subject to production of evidence of losses on account of delay in receipt of material by the contractor. In one of the case, work could not be carried out due to non-supply of cement by the owner and contractor claimed for loss of overheads and profits. The arbitrator rejected the claim on the basis that there was no evidence to support the claim. He was looking for proof of actual payment made by the contractor to prove losses due to overhead and income tax return showing percentage of profit in other contracts to assess the loss in profit. Similarly in another case too, there was delay in the owner's supplies and non availability of equipment. The contractor neither furnished any details to substantiate the claim, nor produced any evidence, nor did he raise any claim during the progress of the work and the entire claim on account of delay in supply of material was made at the end along with other claims. Due to not issuing a notice on time about the delay and not claiming for compensation on time with proper documentary evidence substantiating the losses, the arbitrator denied this claim as a last minute claim. These have led to the following three questions:

- Whose responsibility was it to supply resources?

- Whether the claim of the contractor is supported by the documentary evidence?

- Whether notice was given by the contractor?

In yet another case, the delay in supply of material was attributable to the owner and the compensation was allowed as the delay in supply of material caused the idling of other resources of the contractor. But, the owner did not levy liquidated damages and also allowed extension of time. This led the arbitrator to conclude that the owner and not the contractor was responsible for delay and publish his award in favour of the contractor. These issues are addressed by incorporating the following questions.

- Did delay in mobilization of the particular resource cause idling of some other resources (men and machinery) and was that proved?

- Did the owner invoke liquidated damage clause with or without its actual imposition?

In one settled court cases (Messers Bindra Builders vs Delhi Development Authority ArbLR 1986 (1) 1-6) it was found that as per the contract specification the work required use of 'Makarana marble' for the flooring, but due to non-availability of this type of marble the contractor used alternate type of marble called 'Rajnagar marble'. There was a dispute in settlement of rate for the changed item which raised several queries leading to appointment of arbitrator by the court. Such situations lead to delay in approval of material and then the rates for the item. The entire process eventually delays the progress of the work. Thus this case gives the question - whether non-availability of a particular resource necessitated use of alternate resource and its approval leading to delay?

Thus in this domain a total of seven factors are identified as below for the subsequent study:

Chaphalkar, N and Iyer K C (2014) 'Factors influencing decisions on delay claims in construction contracts for Indian scenario', Australasian Journal of Construction Economics and Building, 14 (1) 32-44 
Q.1 Did the delay in supply of a particular resource affect the schedule of work?

Q.2 Whose responsibility was to supply resources?

Q.3 Was notice regarding the delay in mobilization of a particular resource served by the owner/contractor?

Q.4 Did delay in mobilization of the particular resource cause idling of some other resources (men and machinery) and was that proved?

Q.5 Did the non-availability of a particular resource necessitated the use of an alternate resource and did its approval to delay?

Q.6 Did owner invoke liquidated damage clause with or without its actual imposition?

Q.7 Was the claim by contractor on this issue supported by documentary evidence?

\section{Identification of Factors under Delay due to 'Change Order"}

The nature of construction industry is such that full scope of work cannot be decided at the time of tendering and change orders are inevitable for successful completion of the project. Subsurface conditions and owner's changing requirement are often unpredictable leading to extra work. Change orders causing extra work is identified as a major source of disputes in case of residential building projects, particularly when users and the owner/engineers are two different entities. Generally the issues involved in the change orders are extra time that is required to be provided and the rates at which the contractor is asked to carry out the change order. In spite of well defined contract conditions, they become source of dispute mostly due to attitudinal problems of the parties that prompt disputes (lyer et al 2001). Also in contract condition there is a clause which states the percentage variation which is to be born by the contractor (CPWD clause12, MES clause 7). Therefore the contractor is entitled for the claim only when the variation in quantity exceeds the prescribed limit.

Sometimes the timing of change order also becomes a source of dispute particularly when it is ordered at the end of the project when the contractor has almost wound up the establishment. Although necessary extensions of time as per the condition of contract is granted, the additional time may be inadequate and contractor requires mobilizing resources afresh. Thus while dealing with the disputes involving change order, it is necessary to identify the root cause which has prompted the change order. Since the study is limited to disputes related to delay claims, questions pertaining to this aspect only are considered. Accordingly the followings questions are considered.

- Was change order issued on account of differing site condition or change in specifications?

- Was change order issued due to addition in scope of work?

- Was the additional work due to change order within the deviation limit?

From the case studies, only six cases could be identified that were related to disputes due to delay due to change order. In a case, there was delay due to extra work ordered by the owner, but the compensation was denied to the contractor as he did not furnish any details to substantiate the claim. Another case pertained to change order involving some imported filling materials in the railway project in a tunnel section. The project was completed in 40 months as against the original duration of 15 months. The delay was purportedly due to import of material that was not locally available. Only partial compensation, $51.3 \%$ of the claim amount was allowed to the contractor as certain bills were not produced. These cases led to the question - whether the claim of the contractor is supported by the documentary evidence? 
In yet another case the delay due to variations and extra items was attributable to the owner and the compensation was allowed as the owner did not levy liquidated damages, but allowed extension of time. Hence the arbitrator concluded that the owner was responsible for delay and the claim of the contractor was allowed. This issue is addressed by incorporating the question - did owner invoke liquidated damage clause with or without its actual imposition?

In case of the additional work due to change order, it should be expressly made clear by the contractor that he is not doing the work as a complimentary service, but expects the compensation for that before accepting the work by giving notice to the owner. Although there is an express provision in the Indian Contract Act (Section 70) that a person (the owner) enjoying benefit of non-gratuitous act of the other person (the contractor) is bound to make compensation to the latter, yet the absence of notice from the contractor asking for settlement of rates before commencement of such extra work becomes a contentious issue. This issue is taken care by the question - whether the notice was given by the contractor?

As discussed for the late handing over of site in the previous section, it is also thought appropriate to check whether the delay due to change order actually affected the project schedule. Thus a total of seven factors are identified in this domain as given below.

Q.1 Did change order affect the work schedule?

Q.2 Was change order issued on account of differing site condition or change in specifications?

Q.3 Was change order issued due to addition in scope of work?

Q.4 Was the additional work due to change order within the deviation limit?

Q.5 Was the schedule and cost implications (additional time and money) due to the change order notified by the contractor to the owner?

Q.6 Did owner invoke liquidated damage clause with or without its actual imposition?

Q.7 Was the claim by contractor on this issue supported by documentary evidence?

\section{Identification of Factors under Delay due to 'Release of Payment of RA bills I Mobilization Advance/Escalation"}

A total of six awards were available involving the issue of delay due to payments. The construction contract involves different types of payments like, mobilization advance; running account bill, final bill which when delayed can delay the project. Normally contractors plan their finances considering the cash inflow of the part of the work completed. If they do not get the payment, naturally the project is hampered.

Reason for the running payment being withheld is generally due to substandard work or work not conforming to specifications by the contractor. In case of substandard work, it is generally assumed that the default totally lies with the contractor. When a substandard work is observed, contractor is generally issued a formal notice to improve the quality of work failing which his work will be suspended till the contractor showed due diligence to improve upon the quality of work. However, if the contractor is not served appropriate notice on time either in the certified copy of the running bill or through a separate letter, the owner is not in a position to levy liquidated damages in spite of an express provision in the contract. On the other hand, the rework on account of work not conforming to specifications may be the result of improper communication or interpretation by contract administrators. 
The other reason for withholding payment is that the owner faces cash flow problems leading to delay in making payment. The contractor in this case becomes eligible for a claim of interest charges on the delayed payment.

Many contracts cater for provision of a mobilization advance by the owner at the commencement stage of a project to reduce the burden of mobilizing the resources of the contractor. In the event of a delay in release of this amount, it is likely that the expected fund flow of the contractor is affected; thereby affecting the project schedule. When there is a delay in the release of the amount, it is the duty of the contractor to bring it to the notice of the owner that such an act would affect the project duration and cost. It is owner's right to know the implications of his acts so that he might reconsider his actions of delaying payments. In one of the case, there was a delay in payment by the owner which was proved, but as no notices of damages were given by the contractor to the owner while accepting the extension of time by the contractor the arbitrator denied the claim.

In four cases, the contractor claimed for compensation for his overstay due to non payment of final bill on time but he could not prove the overstay claim by adducing evidences. Hence the claim of the contractor was rejected by the arbitrator. Taking the logics given in the preceding sections, some common factors are included in this domain too and a total of seven factors as given below are identified.

Q.1 Did the delay in payment to contractor affect the schedule of work?

Q.2 Did contractor give notice regarding the delay in the release of payment?

Q.3 Was the delay in payment due to cash flow problem on the owner's side?

Q.4 Was the delay in payment due to delay in decision on fixing of rates for particular item or admissibility of escalation claim, etc.?

Q.5 Was the delay in payment due to withholding of payment pending rectification of bad work or other defaults?

Q.6 Did owner invoke liquidated damage clause with or without its actual imposition?

Q.7 Was the claim by the contractor on this issue supported by documentary evidence?

\section{Identification of Factors under Delay due to 'Subcontractor/Vendor/Another Agency"}

In many construction projects, some jobs are specialized and are assigned to a specialized agency, with expertise in the field. Alternatively, the owner may appoint the agency. Sometimes, in an industrial building contract where the equipment is to be supplied and installed by the contractor and the equipment is to be procured by the main contractor from a particular vendor, there is a delay in the supply of the equipment by the vendor to the main contractor causing delay to project. These delays are considered as third party delay and the contractor may be exempted from paying compensation to the owner. Also in some settled cases (Municipal Corporation of Delhi vs Jagan Nath Ashok Kumar ArbLR 1987(2) 344-348, Delhi Development Authority vs Polo Singh \& Co. ArbLR 2003(1) 270-279, Prem Chand Sharma \& Co vs Delhi Development Authority ArbLR 2003(1) 417-420, Northern Sanitation vs Hotel Corporation of India ArbLR 2005(1) 276-297) it was found that 'another agency', which has been assigned some part of the job by the owner, did not do his part of work. Delay by 'another agency' in completing his part of the job had the serial effect in several other contracts following the 'another agency'.

Only six cases could be identified in this domain. In a typical case, the subcontractor appointed by the contractor abandoned the work, delaying the project. Arbitrators concluded that since the subcontractor was appointed by the contractor, the contractor was responsible

Chaphalkar, N and Iyer K C (2014) 'Factors influencing decisions on delay claims in construction contracts for Indian scenario', Australasian Journal of Construction Economics and Building, 14 (1) 32-44 
for the delay and his claim for compensation was not legitimate. In another case the work was delayed by the subcontractor who was appointed by the owner. Here the arbitrator allowed the claim and gave the verdict in favour of the contractor. Hence as far as the issue of subcontracting is concerned it is essential to find who is responsible for the appointment of the subcontractor/vendor and only then is it possible to finalize the compensation to the suffered party.

In yet another case the claimant contractor could not prove the claim and was unable to produce any evidence. Also notice of damage was not served to the owner by the contractor in time. This resulted in rejection of the contractor's claim by the arbitrator.

In one of the cases, the delay was attributable to the owner and the contractor was allowed compensation as the owner did not levy liquidated damages and allowed extension of time. Hence the arbitrator concluded that the owner was responsible for the delay and the claim of the contractor was allowed.

In two other cases, some part of the work was allotted to another agency by the owner and the contractor had to remobilize the resources on account of delay due to non completion of the work by this agency. The arbitrator held the owner responsible and allowed the claims of the contractor.

Thus in this domain a total of seven factors are identified as given below which are taken for the subsequent study.

Q.1 Did delay due to subcontractor/vendor/another agency affect the project schedule?

Q.2 Was subcontractor/vendor/another agency assigned specialized job which the original contractor could not have done?

Q.3 Was the appointment of subcontractor/vendor/another agency approved by the owner?

Q.4 Was notice regarding the delay due to subcontractor/another agency served by owner/contractor?

Q.5 Was the contractor's resources (men and machinery) idled due to delay caused by subcontractor/another agency?

Q.6 Did the owner invoke a liquidated damage clause with or without its actual imposition?

Q.7 Was the claim by the contractor on this issue supported by documentary evidence?

It is observed from the factors identified above in each domain that while all domains have some common factors, there are certain domain specific factors, which are considered important by the arbitrator while giving the decision. It was also observed that in many cases one award covered claims from more than one domain and there was difficulty in segregating the individual claims. Hence such cases could not be considered for identifying the domains. However they are studied to get greater insight of the subject matter.

\section{Conclusion}

This paper identifies the various delay domains and factors influencing the decisions by arbitrators. The factors are identified as questions asked by the arbitrators and viewed as the thought process of arbitrators or judges. These questions are extracted through literature, arbitration awards, court cases and discussions with professionals. As all the factors may not be present in a given case nor will all of them have equal influence in decision making, it is also essential to find out their relative importance. This may be taken as future research. 


\section{References}

Aibinu, A.A., and Jagboro, G.O. (2002) 'The effects of construction delays on project delivery in Nigerian construction industry', International Journal of Project Management, 20, 593-599.

Al-Momani, A.H. (2000) 'Construction delay: a quantitative analysis', International Journal of Project Management, 18, 51-59.

lyer, K.C. and Kalidindi, N.S. (2002) 'Final and Binding Power Clauses in Indian Construction Contracts', International Journal of Project Management, 20, 13-22.

lyer, K.C., Kalidindi, N.S. and Ganesh, L.S. (2001) 'Effects of Construction Contract clauses on occurrence of disputes in India', Asia Pacific Building and Construction Management Journal, 6 (1), 13-24.

Kumarswamy, M.M., andYogeswaran, K. (2003) 'Substantiation and assessment of claims for extension of time', International Journal of Project Management, 21, 27-38.

Odeh, A.M., and Battaineh, H.T. (2002) 'Causes of construction delay: traditional contracts', International Journal of Project Management, 20, 67-73.

Satyanarayana, K.N. and Iyer, K.C. (1996) 'Evaluation of delays in Indian construction contracts', Journal of the Institution of Engineers (India), Vol.77, September 1996, 14-22.

Scott, S. (1997) 'Delay Claims in U.K. Contracts', Journal of Construction Engineering and Management, ASCE, 123 (3), 238-244.

Scott, S., Harris, R.A., and Greenwood, D. (2004) 'Assessing the New United Kingdom Protocol for Dealing with Delay and Disruption', Journal of Professional Issues in Engineering Education and Practice, ASCE, 130 (1), 50-59.

Yates, J.K. and Epstein, A. (2006) 'Avoiding and Minimizing Construction Delay Claim Disputes in Relational Contracting', Journal of Professional Issues in Engineering Education and Practice, ASCE, 132 (2), 168-179. 